\title{
Mireille Labouret-Grare, Balzac, La Duchesse et l'idole, Poétique du corps aristocratique
}

\section{(2) OpenEdition \\ Journals}

Édition électronique

URL : https://journals.openedition.org/studifrancesi/39601

DOI : 10.4000/studifrancesi.39601

ISSN : 2421-5856

Éditeur

Rosenberg \& Sellier

Édition imprimée

Date de publication : 1 décembre 2004

Pagination : 392

ISSN : 0039-2944

\section{Référence électronique}

"Mireille Labouret-Grare, Balzac, La Duchesse et l'idole, Poétique du corps aristocratique », Studi Francesi [En ligne], 143 (XLVIII | II) | 2004, mis en ligne le 30 novembre 2015, consulté le 19 mai 2021. URL : http://journals.openedition.org/studifrancesi/39601; DOI : https://doi.org/10.4000/studifrancesi. 39601

Ce document a été généré automatiquement le 19 mai 2021.

\section{c) $(1) \Theta$}

Studi Francesi è distribuita con Licenza Creative Commons Attribuzione - Non commerciale - Non opere derivate 4.0 Internazionale. 


\section{Mireille Labouret-Grare, Balzac, La Duchesse et l'idole, Poétique du corps aristocratique}

\section{RÉFÉRENCE}

MireIlle Labouret-Grare, Balzac, La Duchesse et l'idole, Poétique du corps aristocratique, Paris, Honoré Champion, 2002, pp. 495.

1 L'ouvrage de M. Labouret se présente en trois parties. Équilibrées, la première et la troisième («Le Corps, passerelle entre nature et culture» et «Poétique du corps aristocratique») encadrent une partie centrale plus brève: «Métaphores du corps, l'ange et la bête». Consacré à l'aristocrate, le livre se réfère à maints romans de $L a$ Comédie humaine et à des oeuvres non romanesques. Néanmoins, l'accent est mis sur La Peau de chagrin, La Femme de trente ans, Mémoires de deux jeunes mariées, La Duchesse de Langeais, Les Secrets de la princesse de Cadignan, Le Lys dans la vallée, Béatrix.

2 À petites touches (et cela est fort heureux), l'auteur sait user de sa parfaite connaissance de la vie de Balzac. Sur l'œuvre, des travaux anciens parfois peu connus sont utilisés avec probité et bonheur et la bibliographie balzacienne, en ses tendances si diverses, est activement présente. Au fait de la tradition, M.Labouret est en même temps résolument moderne. Jamais, par exemple, elle ne s'engage dans une recherche de sources (voir la note 28, p. 187), mais elle s'arme avec discernement de la sémiotique et de la narratologie. Par ailleurs, pour offrir au lecteur un «support référentiel», elle présente, sous forme de tableaux, un relevé très clair des modes d'insertion du portrait aristocratique dans le récit (p. 314-322); en pleine page (p. 207), elle dessine même une roue symbolique sur laquelle s'étagent, du serpent à l'oiseau, les métaphores animales. Elle tient compte de l'histoire de l'oeuvre, des variantes (si éclairantes par exemple pour l'évolution du personnage de Marie de Verneuil dans Les Chouans). Surtout elle s'attache à l'analyse la plus complète, la plus rigoureuse et minutieuse du texte, toujours délicatement subtile et mesurée, révélant de chatoyants réseaux 
métaphoriques, toute une polyphonie discursive, faisant entendre de lointains échos, parfois inouïs pour une oreille moins exercée, et n'oubliant jamais la discrète ironie de l'auteur à son propre égard. Mais, dans l'ordre de l'esthétique, de la morale, les hypothèses, les résultats sont interrogés, considérés à la lumière (entre autres) de Kant et de Hegel, de Levinas et de Ricoeur. De plus, l'oeuvre du romancier-historien apparaît clairement, point essentiel, gorgée d'imaginaire, toujours proche du mythe (et le recours à Mircea Eliade, à G.Durand installe d'intéressants arrière-plans). Permanent est l'effort de mise en perspective. Tout est vu de très près et à distance à la fois.

On peut ne pas être d'accord avec toutes les assertions: par exemple la fin de Mme Willemsens -dans La Grenadière- est-elle vraiment orchestrée dans un final cosmique? Rattacher Lady Dudley à la catégorie des anges, même dévoyés, n'est-ce pas un peu surprenant? Mais ce sont là points de détail. Importe la force de la thèse: au corps mondain artificiel et théâtral s'oppose celui de la femme naturelle (grande dame ou femme vénale), lié aux éléments premiers, eau, terre et feu. Le type balzacien de l'aristocrate, que révèle l'étude des portraits et du langage du corps, est marqué d'abord par le sublime de la faute. Il va se dégradant. D'autres figures sublimes prennent le relais.

4 Un style clair, pédagogique au noble sens du terme, refusant l'ellipse facile, s'émaille d'heureuses, de belles formules qu'on ne saurait relever. Quelques rares coquilles cependant: notons «elle, expire» au lieu de «elle, expie», p. 233; lisons p. 473: «P. Nykrog» et non «P. Nykrok». Au vrai, manque un index rerum (mais peut-être est-ce question de normes éditoriales): thématique, narratologique, il aurait heureusement complété ce remarquable ouvrage, en aurait rendu l'usage encore plus fécond.

Il est notable, et combien estimable, que ce travail de 1988 ait été médité de nouveau (il n'avait nul besoin d'être repensé). Non seulement la bibliographie a été mise à jour jusqu'à 2000. Mais surtout les apports de la critique (de Philippe Hamon, d'Arlette Michel, de Catherine Nesci, de Baldine Saint-Girons, de maints autres) ont été intégrés dans le texte, interrogés, discutés (prudemment, mais avec grande fermeté de conviction, voir par exemple la note 2, p. 280), assimilés. Le livre a vécu dans le temps avec son auteur, continuant à creuser son sillon, parmi les autres chercheurs et essayistes. Sa séduction reste intacte. Il est encore plus convaincant. 